\title{
SEQUENCE-DEPENDENT ENHANCEMENT OF PACLITAXEL TOXICITY IN NON-SMALL CELL LUNG CANCER BY 17-ALLYLAMINO 17-DEMETHOXYGELDANAMYCIN
}

Dao M. Nguyen, MD, FRCSC

Aaron Chen, MS

Arnold Mixon, BS

David S. Schrump, MD, FACS

Sponsor: Jack A. Roth, MD
Objective: Overexpression of the oncogene erbB-2 contributes to chemoresistance in various malignant tumors including lung cancer. The aim of this study was to investigate whether depletion of the erbB-2 gene product (p185) by 17-allylamino 17-demethoxygeldanamycin would sensitize lung cancer cells to paclitaxel (Taxol) in vitro. Methods: Paclitaxel cytotoxicity was evaluated in a panel of non-small cell lung cancer cell lines that expressed varying levels of p185 by means in vitro proliferation assays and 2 drug combination schedules. Cell cycle kinetics and apoptosis after exposure to paclitaxel or paclitaxel plus 17-allylamino 17-demethoxygeldanamycin were analyzed by flow cytometry. Results: The 17-allylamino 17-demethoxygeldanamycin treatment efficiently depleted p185 expression in lung cancer cells. Concurrent exposure of these cells to paclitaxel and 17-allylamino 17-demethoxygeldanamycin significantly enhanced paclitaxel-mediated cytotoxicity, particularly in cells which overexpressed p185. There was a 1.3 to more than 20 -fold reduction of paclitaxel $50 \%$ inhibitory concentration values in those cells that were responding positively to the drug combination. Significant induction of apoptosis was observed after treatment of cells with the combination of paclitaxel and 17-allylamino 17-demethoxygeldanamycin. The combination cytotoxic effect was only additive in cells expressing low levels of p185. In contrast, of lung cancer cells with exposure to 17-allylamino 17-demethoxygeldanamycin before combined paclitaxel and 17-allylamino 17-demethoxygeldanamycin exposure actually rendered the cells refractory to paclitaxel cytotoxicity. Conclusion: The compound 17-allylamino 17-demethoxygeldanamycin sensitizes non-small cell lung cancer cells expressing high levels of p185 to paclitaxel-mediated growth arrest and apoptosis. These preclinical data support the evaluation of the combination of paclitaxel and 17allylamino 17-demethoxygeldanamycin in the treatment of patients with lung cancer whose tumors exhibit p185 overexpression. (J Thorac Cardiovasc Surg 1999;118:908-15)
A though still not fully defined, the molecular basis of chemoresistance in cancer appears to be a collective result of many complex genetic factors, one of which is overexpression of the oncogene erbB-2. This oncogene encodes a 185-kd transmembrane receptor glycoprotein (p185) with intrinsic tyrosine kinase activ-

From the Section of Thoracic Oncology, Surgery Branch, Division of Clinical Sciences, National Cancer Institute, National Institutes of Health, Bethesda, Md.

Read at the Seventy-ninth Annual Meeting of The American Association for Thoracic Surgery, New Orleans, La, April 18-21, 1999.

Received for publication April 22, 1999; revisions requested July 12, 1999; revisions received Aug 11, 1999; accepted for publication Aug 17, 1999. ity, ${ }^{1}$ which is overexpressed in $30 \%$ to $40 \%$ of breast carcinoma, ovarian carcinoma, and non-small cell lung cancer (NSCLC). ${ }^{2}$ Recent studies have indicated that p185 overexpression correlates with enhanced cellular resistance to a variety of chemotherapeutic agents, including cisplatin, etoposide, doxorubicin

Address for reprints: Dao M. Nguyen, MD, Senior Investigator, Thoracic Oncology Section, Surgery Branch, NCI/NIH, Room 2b07, Building 10, 10 Center Dr, Bethesda, MD 20892-1502 (E-mail: Dao_Nguyen@nih.gov).

$12 / 6 / 102291$ 
(Adriamycin), and paclitaxel (Taxol)..$^{2-6}$ Overexpression of p185 correlates with poor response to treatment and diminished survival among patients with breast, ovarian, and lung carcinomas. ${ }^{7-9}$

The benzoquinone ansamycin antibiotic geldanamycin and its less toxic synthetic derivative 17-allylamino 17demethoxygeldanamycin (17-AAGA) have recently been selected for clinical development at the National Cancer Institute because of their activity against cell lines derived from a variety of human malignancies. ${ }^{10,11}$ These agents have been shown to inhibit p185 expression in breast and lung cancer cells at nanomolar concentrations. ${ }^{5,12}$ Geldanamycin and 17-AAGA bind to GRP94 (a member of the heat shock protein (HSP) 90 family of stress proteins), displacing p185 and resulting in rapid degradation of this oncoprotein. ${ }^{13,14}$

In this study we sought to evaluate whether 17AAGA-mediated depletion of $\mathrm{p} 185$ could enhance sensitivity to paclitaxel in NSCLC cell lines. Our analysis revealed that inhibition of $\mathrm{p} 185$ expression correlated with enhanced sensitivity to paclitaxel in NSCLC cell lines that constitutively express high levels of this oncoprotein. The synergistic combination effect was dependent on the sequence of drug exposure. Moreover, downward regulation of $\mathrm{p} 185$ expression by 17AAGA in p185-overexpressing cell lines augmented paclitaxel-induced apoptosis.

\section{Materials and methods}

Cell lines and reagents. The NSCLC cell lines H460, H1299, H358, and H322 were available in tissue culture banks at the National Cancer Institute; the NSCLC cell lines H661 and H522 were purchased from American Type Culture Collection (Manassas, Va). Cells were maintained in Roswell Park Memorial Institute media supplemented with glutamine $(2 \mathrm{mmol} / \mathrm{L})$, streptomycin $(100 \mu \mathrm{g} / \mathrm{mL})$ and penicillin $(100$ $\mathrm{U} / \mathrm{mL}$ ), and $5 \%$ or $10 \%$ fetal calf serum (all purchased from BioFluids, Rockville, Md). Normal human bronchial epithelial cells were purchased from Clonetics (BioWhittaker, IncA Cambrex Company, Walkersville, Md). The 17-AAGA, obtained from the Drug Synthesis \& Chemistry Branch, Developmental Therapeutic Program, Division of Cancer Treatment, National Cancer Institute, was dissolved in dimethyl sulfoxide to yield a $100-\mu \mathrm{mol} / \mathrm{L}$ stock solution and stored at $-70^{\circ} \mathrm{C}$. All experiments involving this compound were performed under subdued light conditions. Paclitaxel (Taxol USP) was purchased from Bristol-Myers Squibb Company (New York, NY). MTT (4,5-dimethylthiazo-2-yl)2,5-diphenyl tetrazolium bromide) was purchased from Sigma (St Louis, Mo). Cellular p185 levels were measured with an enzyme-linked immunosorbent assay kit from Oncogene Science Diagnostics (Cambridge, Mass).

In vitro cell proliferation and drug combination schedules. Cells were seeded in flat-bottom 96-well microtiter plates at densities predetermined for each cell line to avoid confluence at the end of experiments. After an overnight incubation, cells were treated either with paclitaxel alone or with the combination of paclitaxel and 17-AAGA according to the following schedules.

Schedule A. A 90-minute exposure to varying doses of paclitaxel concurrently with 17-AAGA $(20,40$, or 80 $\mathrm{nmol} / \mathrm{L}$ ) was followed by 2 washes with phosphate-buffered saline solution to remove unbound drugs and then further incubated for 96 hours in media containing appropriate concentrations of 17-AAGA.

Schedule B. A 24-hour 17-AAGA exposure was followed by concurrent drug exposure identical to that in schedule A.

Both schedules. In both schedules 17-AAGA was continuously present in the culture media with replenishment every 48 hours; this was essential because the effect of 17-AAGA on p185 depletion has been shown to be short-lived and reversible. ${ }^{15}$ At the end of the incubation period viable cells were quantitated by MTT colorimetric assays as described by the manufacturer. Paclitaxel dose-response curves of cells treated with paclitaxel alone were plotted as fraction of viable cells relative to cells grown in normal media versus paclitaxel doses, whereas those of cells treated with the paclitaxel and 17-AAGA combination were plotted as fraction of viable cells relative to cells grown in 17-AAGA-containing media (to correct for the minor growth inhibitory effect of 17AAGA) versus paclitaxel doses. Paclitaxel 50\% inhibitory concentration $\left(\mathrm{IC}_{50}\right)$ values for cells treated with paclitaxel alone or paclitaxel in combination with 17-AAGA were derived from the respective dose-response curves. A reduction of paclitaxel $\mathrm{IC}_{50}$ values in cells treated with the drug combination indicated and increase by 17-AAGA in the cellular responsiveness to paclitaxel's cytotoxic effects.

Flow cytometric analysis of cell cycle kinetics and apoptosis. Cell cycle kinetics and programmed cell death in nonsynchronized cells grown in the presence or absence of drugs were analyzed by propidium iodide staining ${ }^{16}$ and TUNEL (terminal deoxynucleotidyltransferase-mediated dUTP nick end labeling) method using the Apo-BRDU kit (Phoenix Flow Systems, San Diego, Calif) respectively and the FACScan apparatus (Becton Dickinson and Company, Franklin Lakes, NJ).

Statistical analysis. Data are expressed as mean \pm SD. The Student $t$ test and 1-way analysis of variance (with Bonferroni test for pairwise comparisons) were used for statistical analysis with the Prism 2.0 software package from GraphPad Software, Inc (San Diego, Calif).

\section{Results}

Constitutive p185 expression in NSCLC. In preliminary studies p185 expression in NSCLC cells was quantitated with enzyme-linked immunosorbent assay techniques. This analysis indicated that $\mathrm{H} 460$ and H1299 cells expressed relatively low levels of p185 (4.3 and 6.5 erbB-2 units/ $\mu \mathrm{g}$ protein, respectively), 


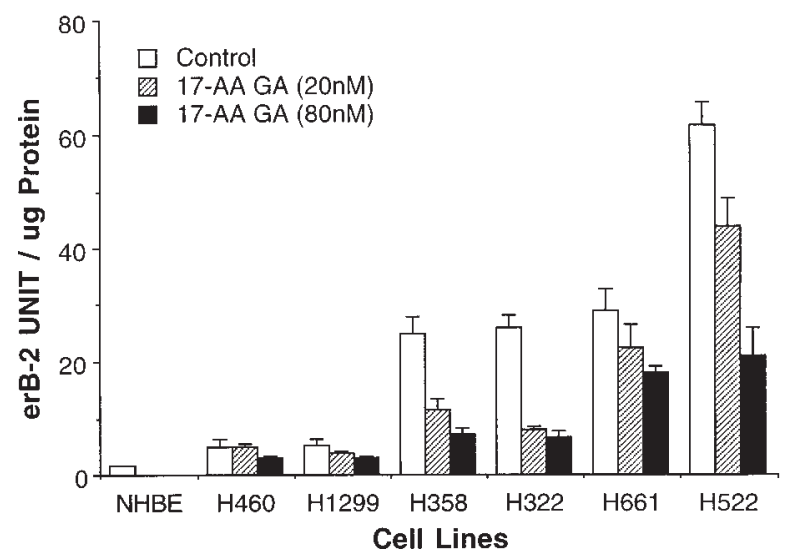

Fig 1. Constitutive expression of p185 oncoprotein and its depletion by 17-AAGA in NSCLC cells. Normal human bronchial epithelial cells (NHBE) as well as H460 and H1299 cells express low levels of p185. Other cell lines overexpress this oncoprotein (15- to 31-fold higher than level detected in normal human bronchial epithelial cells). Exposure to either $20 \mathrm{nmol} / \mathrm{L}$ or $80 \mathrm{nmol} / \mathrm{L}$ 17-AAGA for 24 hours resulted in dose-dependent reduction of p185 in all cell lines tested. Data are mean \pm SD for 3 independent experiments.

which nevertheless were 2.5- to 3.5-fold higher than the level of p185 expression in confluent normal human bronchial epithelial cells. The other NSCLC lines expressed extremely high levels of this oncoprotein, ranging from 25 to $52 \mathrm{erbB}-2$ units $/ \mu \mathrm{g}$ protein (15- to 31 -fold the level detected in primary normal human bronchial epithelial cells; Fig 1). A 24-hour exposure to either 20 or $80 \mathrm{nmol} / \mathrm{L}$ 17-AAGA resulted in a significant dose-dependent reduction of p185 levels in all NSCLC lines, regardless of their intrinsic levels of p185 expression (Fig 1). These results were consistent with previously published data concerning depletion of p185 in NSCLC cells after exposure to 17AAGA. $^{3,6}$ In parallel with the inhibition of p185 expression, continuous exposure to 17-AAGA for 96 hours resulted in a dose-dependent inhibition of NSCLC cell proliferation, with estimated $\mathrm{IC}_{50}$ values ranging from 60 to $180 \mathrm{nmol} / \mathrm{L}$ (Fig 2).

Sequence-dependent enhancement of paclitaxel cytotoxicity by 17-allylamino 17-demethoxygeldanamycin. The treatment schedules were designed to determine whether downward regulation of p185 expression by 17-AAGA would enhance sensitivity of NSCLC cells to paclitaxel. In schedule A the 17AAGA-mediated depletion of p185 occurred concurrently with paclitaxel's effects on microtubules. Representative dose-response curves of H661 (high p185) and H1299 (low 185) cells treated with paclitaxel alone or with the paclitaxel and 17-AAGA combina-

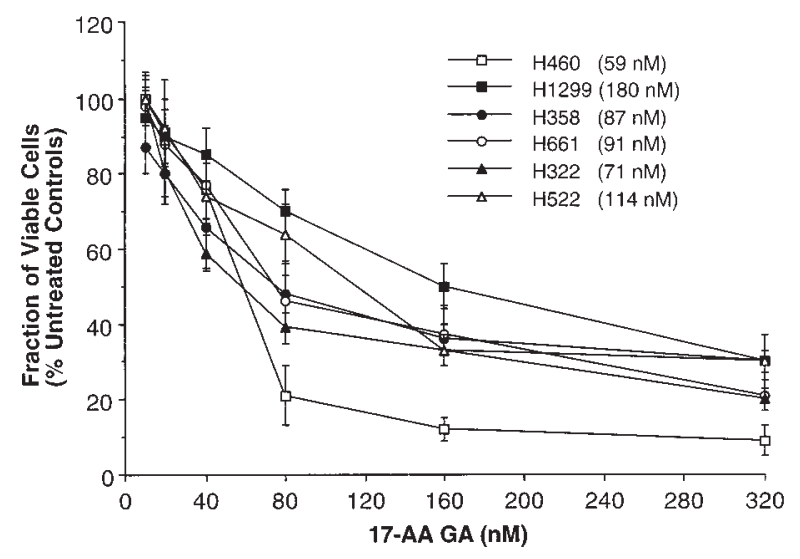

Fig 2. Dose-dependent growth inhibition of NSCLC in vitro by 17-AAGA. Cells were seeded in 96-well flat-bottom microtiter plates and, after overnight incubation, continuously exposed to varying doses of 17-AAGA for 96 hours. Viable cells were quantitated by MTT assay. $\mathrm{IC}_{50}$ values, estimated from dose-response curves, are indicated in parentheses. Data are mean \pm SD for 3 independent experiments.

tion (schedule A) are shown in Fig 3, A. The added suppression of cell growth by the drug combination in H661 cells (20\%-30\%) compared with cells treated with paclitaxel alone was higher than the growth inhibitory effect of 17-AAGA (10\%-15\% growth inhibition at 20 and $40 \mathrm{nmol} / \mathrm{L}$, respectively). The combination effect was clearly synergistic. There was a significant dosedependent 17-AAGA-mediated reduction of paclitaxel $\mathrm{IC}_{50}$ values in $\mathrm{H} 661$ cells treated with the drug combination, indicating enhanced sensitivity to paclitaxel's cytotoxic effects: $100 \pm 11 \mathrm{nmol} / \mathrm{L}$ and $71 \pm 8 \mathrm{nmol} / \mathrm{L}$ in cells treated with the drug combination at $20 \mathrm{nmol} / \mathrm{L}$ and $40 \mathrm{nmol} / \mathrm{L} 17$-AAGA versus $400 \pm 23 \mathrm{nmol} / \mathrm{L}$ in cells treated with paclitaxel alone $(P=.0011$ and $P=$ .0006 by the Student $t$ test, respectively). On the other hand, combination drug exposure had only an additive cytotoxic effect in H1299 cells; further reduction of the fractions of survival in the combination-treated cells was entirely attributable to the antiproliferative effect of $17-\mathrm{AAGA}$ ( $5 \%$ to $15 \%$ growth inhibition at $20 \mathrm{nmol} / \mathrm{L}$ and $40 \mathrm{nmol} / \mathrm{L}$ 17-AAGA, respectively).

Fig 3, B, depicts the effects of combination drug treatment on paclitaxel sensitivity in the panel of NSCLC cell lines. Enhancement of paclitaxel cytotoxicity by 17-AAGA was observed only in cells that expressed high levels of $\mathrm{p} 185$. The magnitude of sensitization (expressed as the multiplicity of reduction in paclitaxel $\mathrm{IC}_{50}$ values) in each cell line is depicted in the graph located in the upper right corner of Fig $3, B$.

Impressed with the ability of 17-AAGA to enhance paclitaxel sensitivity with schedule A, we next examined 

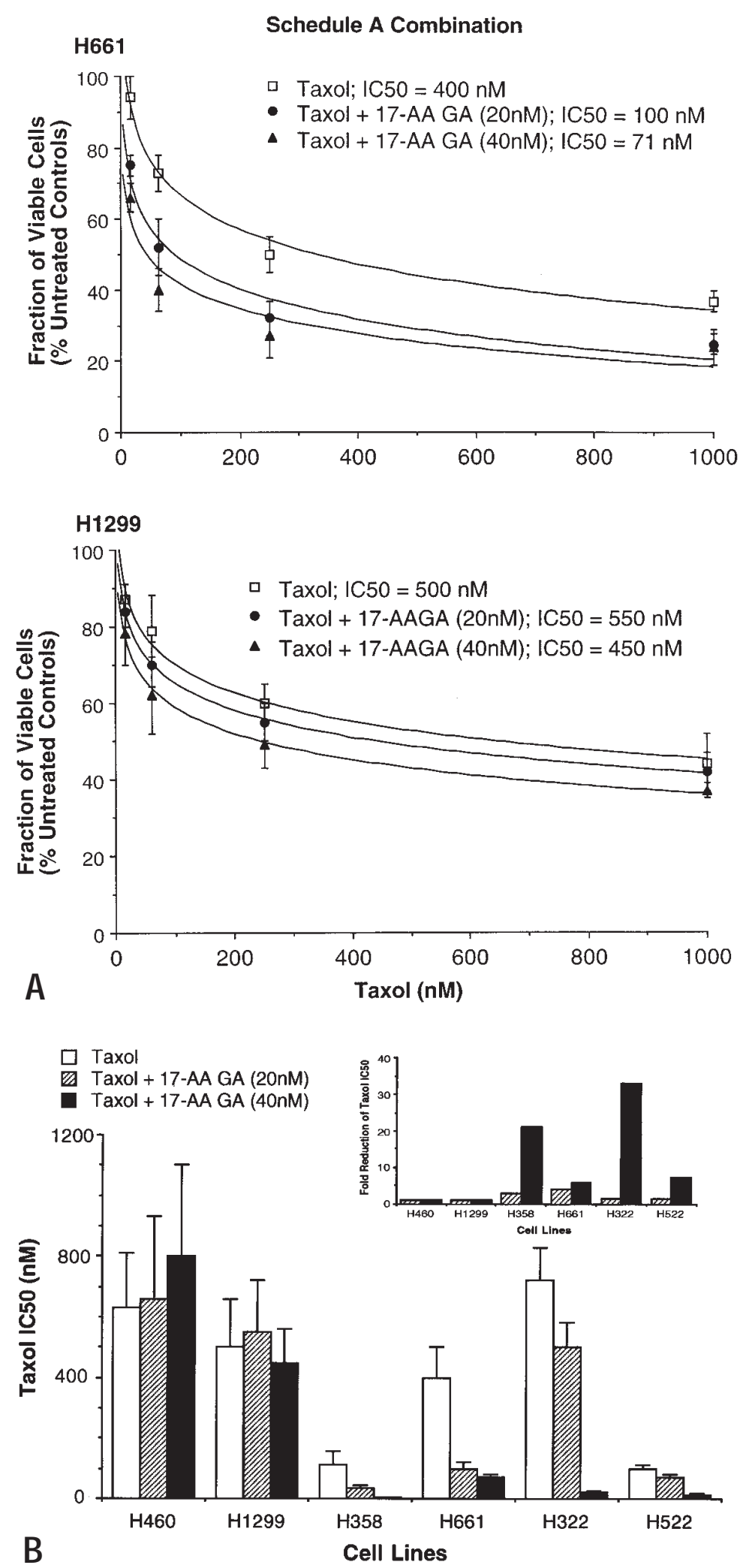

Fig 3. A, Representative dose-response curves of H661 (high p185) and H1299 (low p185) cells treated with paclitaxel (Taxol) alone or concurrently with either $20 \mathrm{nmol} / \mathrm{L}$ or $40 \mathrm{nmol} / \mathrm{L}$ 17-AAGA (schedule A combination). Data are mean \pm SD for 4 independent experiments. B, Reduction of paclitaxel (Taxol) $\mathrm{IC}_{50}$ values by $17-\mathrm{AAGA}$ in NSCLC cells expressing high levels of p185 ( $P=.001, P<.0001, P<.0001, P<.0001$ for H358, H322, H661, and $\mathrm{H} 522$ cells, respectively, by 1-way analysis of variance). Data are mean \pm SD for 4 independent experiments. Right upper corner graph indicates multiplicity of reduction of paclitaxel $\mathrm{IC}_{50}$ values (indicating enhanced paclitaxel sensitivity) in cells treated with paclitaxel and either $20 \mathrm{nmol} / \mathrm{L}$ or $40 \mathrm{nmol} / \mathrm{L} 17-A A G A$. 

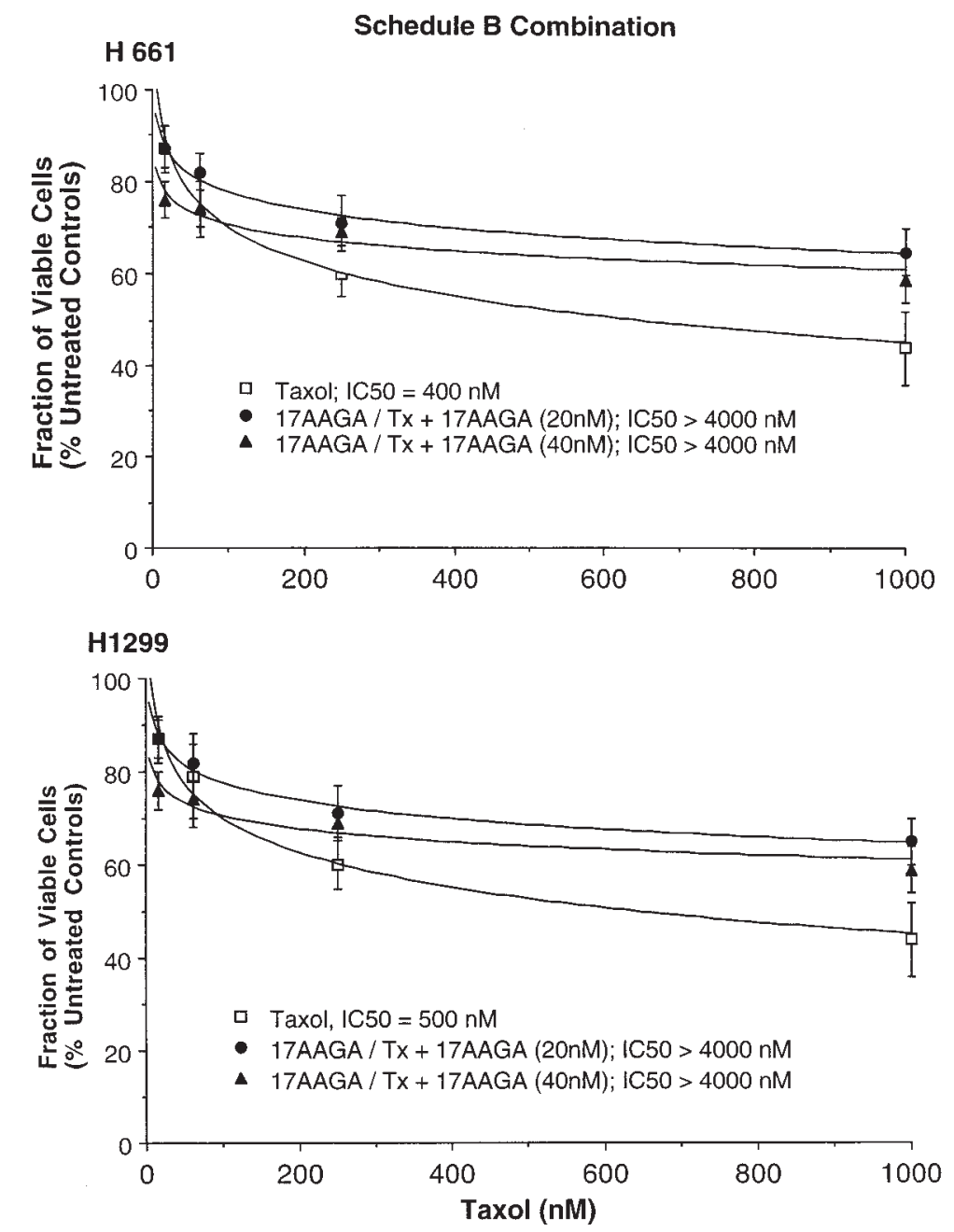

A

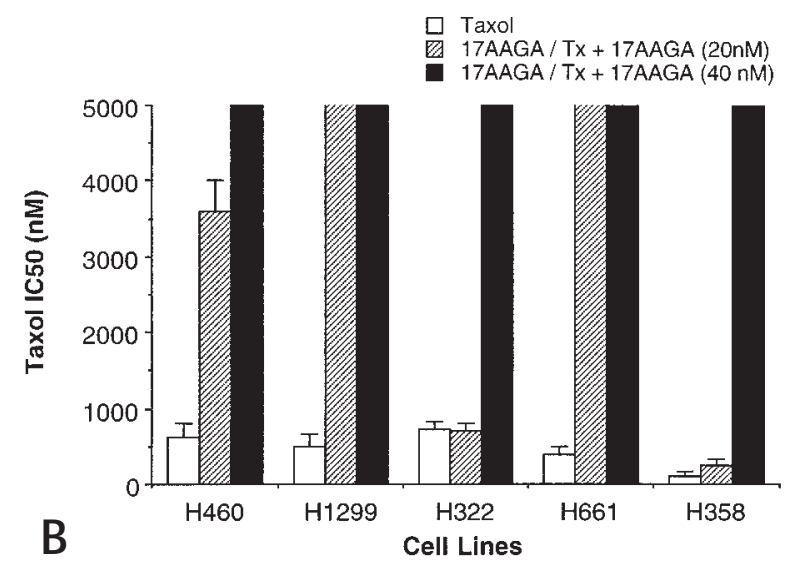

Fig 4. A, Representative dose-response curves of H661 (high p185) and H1299 (low p185) cells treated with paclitaxel (Taxol, Tx) or schedule B drug combination. Exposure of cells to 17-AAGA for 24 hours before paclitaxel and 17-AAGA treatment induced paclitaxel resistance, as indicated by higher fractions of viable cells and translated into elevation of paclitaxel $\mathrm{IC}_{50}$ values. Data are mean $\pm \mathrm{SD}$ for 4 independent experiments. B, Significant elevation of paclitaxel $\mathrm{IC}_{50}$ values (indicating decreased paclitaxel sensitivity) by schedule $\mathrm{B}$ drug combination in 5 cell lines studied ( 2 low p185 and 3 high p185 cell lines). 


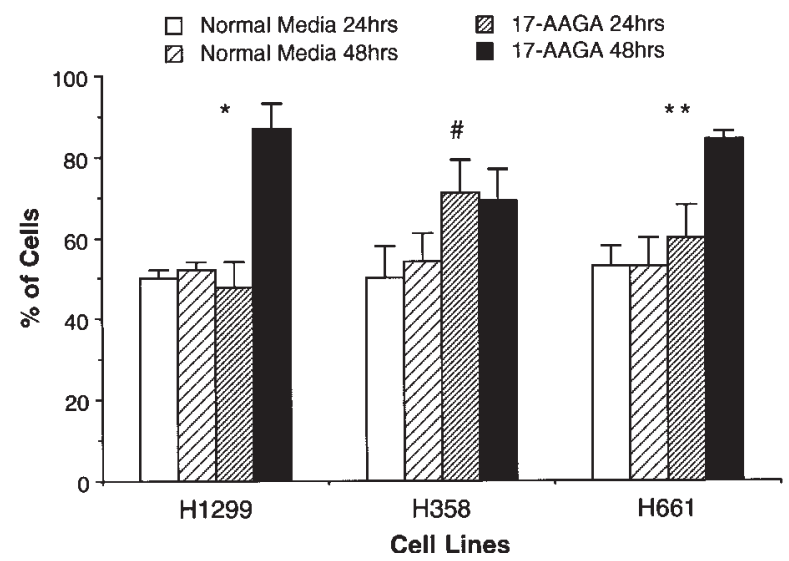

Fig 5. Time-course of induction of cell cycle arrest at $\mathrm{G}_{1}$ phase by 17-AAGA treatment in H1299, H661, and H358 ( $P$ $=.42$ and $\mathrm{P}<.0001$ [asterisk], $P=.01$ and $P=.03$ [number sign], and $P=.19$ and $P=.0001$ [double asterisk] for 17AAGA treatment versus control at 24 hours and 48 hours, respectively, by the Student $t$ test). Data are mean \pm SD for 3 independent experiments.

whether pretreating cells with 17-AAGA before combination drug exposure (schedule B) would further potentiate the effects of paclitaxel. Preliminary experiments revealed that treating cells with 17-AAGA for 24 hours enabled maximum inhibition of p185 expression (data not shown). Interestingly, instead of sensitizing cells to paclitaxel, 17-AAGA pretreatment rendered NSCLC cells more resistant to this combination. Representative dose-response curves of H661 and H1299 cells treated with paclitaxel alone or with the schedule B drug combination are depicted in Fig 4, A. Higher fractions of viable cells after treatment with this drug combination were translated into high paclitaxel $\mathrm{IC}_{50}$ values and thus paclitaxel resistance. The drastic increase in paclitaxel $\mathrm{IC}_{50}$ values observed with this drug combination (summarized in Fig 4, B) was noted in all cell lines irrespective of their levels of p185 expression.

Cancer cells exhibit marked sensitivity to paclitaxel during $\mathrm{G}_{2}-\mathrm{M}$ phase yet are quite resistant to microtubule damage during $G_{1}$ phase. ${ }^{17,18}$ Flow cytometric analysis revealed that 17-AAGA induced a $\mathrm{G}_{1}$-phase arrest in NSCLC cells, noted within 24 to 48 hours of exposure (Fig 5); the profound $\mathrm{G}_{1}$-phase arrest induced by 17 AAGA may have rendered these cells refractory to the cytotoxic effects of subsequent paclitaxel treatment.

Enhanced induction of apoptosis by the paclitaxel and 17-allylamino 17-demethoxygeldanamycin combination. Propidium iodide staining and TUNEL assay analyses of cell cycle kinetics and apoptosis were performed to investigate the mechanism of the synergistic cytotoxic effect of the paclitaxel and 17-AAGA (sched-

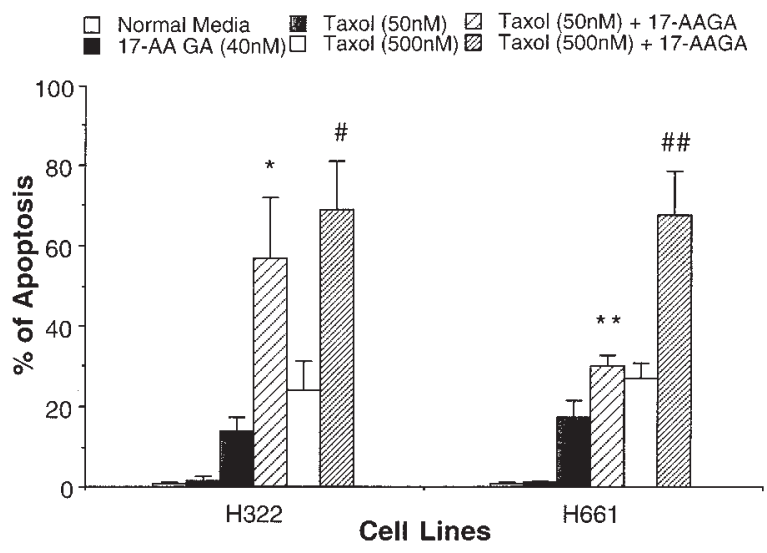

Fig 6. Significant induction of apoptosis in H322 and H661 cells treated for 60 hours with schedule A combination (paclitaxel [Taxol] at $50 \mathrm{nmol} / \mathrm{L}$ and $500 \mathrm{nmol} / \mathrm{L}$ and $17-\mathrm{AAGA}$ at $40 \mathrm{nmol} / \mathrm{L})$. Control preparations were cells treated either with 17-AAGA or with paclitaxel $(P=.0001$ [asterisk], $P=$ .0008 [number sign], $P=.001$ [double asterisk], and $P=$ .0001 [double number sign] for schedule A combination versus paclitaxel alone by Student $t$ test. Data are mean \pm SD for 3 independent experiments.

ule A) drug combination in NSCLC cells. H322 cells treated with schedule A exhibited a $\mathrm{G}_{2}-\mathrm{M}$-phase arrest within 18 hours of drug exposure; this cell cycle arrest peaked at 48 hours, coinciding with the onset of apoptosis. Cells exposed only to paclitaxel followed a similar time course of $\mathrm{G}_{2}-\mathrm{M}$-phase arrest and induction of apoptosis, albeit at a much lower magnitude (data not shown). On the other hand, 17-AAGA primarily induced $\mathrm{G}_{1}$-phase arrest (Fig 5). Paclitaxel and 17AAGA combination therapy induced extensive apoptosis in H322 and H661 NSCLC cells (Fig 6), exceeding that observed in cells treated with paclitaxel alone. For instance, in $\mathrm{H} 322$ cells, $57 \% \pm 15 \%$ and $69 \% \pm 12 \%$, respectively, of apoptotic cells were detected after treatment with paclitaxel and 17-AAGA at 50 and 500 $\mathrm{nmol} / \mathrm{L}$, as compared with $14 \% \pm 4 \%$ and $24 \% \pm 5 \%$ of apoptotic cells after exposure to paclitaxel $(P=.0001$, $P=.0008)$. No apoptosis was observed after 17-AAGA treatment alone.

\section{Discussion}

Appreciation of the molecular basis of chemoresistance may enable the development of pharmacologic regimens that are selective and efficacious against high-risk cancers. In recent years the erbB-2 oncogene has attracted considerable attention as a potential target for anticancer therapy. Overexpression of the erbB-2 gene has been detected in a wide variety of tumors, correlating with increased basal secretion of vascular 
endothelial growth factor ${ }^{19}$ and matrix metalloproteinases with increased propensity for systemic metastases $^{20}$ as well as with chemoresistance ${ }^{2-6}$ in these neoplasms. Inhibition of p185 protein expression or function (by anti-p185 monoclonal antibodies that target the extracellular moiety of the molecule ${ }^{21}$ or by gene therapy techniques that use antisense oligonucleotides or gene sequences encoding an intracellular anti-p185 single-chain antibody ${ }^{22}$ ) induces growth arrest in cancer cells. Such strategies may have limited clinical utility because of technical issues pertaining to the delivery of therapeutic macromolecules to tumor cells. Therefore the identification of low-molecularweight molecules such as 17 -AAGA that deplete p185 molecule protein levels at nanomolar concentrations is of particular interest and practical application.

The mechanisms of antitumor activity mediated by geldanamycin and 17-AAGA have been well characterized. ${ }^{11-14}$ At low concentrations geldanamycin and 17AAGA interact with HSP90 and its homologs to disrupt their chaperone functions. A myriad intracellular molecules that normally associate with HSP90 are affected by these compounds, namely Raf- 1 , mutant $\mathrm{p} 53$, cyclindependent kinase 4, and p185. In addition to p185 depletion, geldanamycin and 17-AAGA deplete Raf-1, shorten the half-life of oncogenic p53 mutants, and destabilize newly synthesized cyclin-dependent kinase 4. The effects of geldanamycin and 17-AAGA on the expression of these growth-promoting proteins contribute to the antiproliferative properties of these drugs. ${ }^{11}$ Hence it is possible that 17-AAGA enhances paclitaxel sensitivity in NSCLC cells by mechanisms other than p185 depletion. No changes in Raf-1 levels have been observed in NSCLC cells after 48 hours of exposure to 17-AAGA at the concentrations employed in this study (data not shown). Moreover, inhibition of p185 function by the anti-p185 humanized monoclonal antibody Herceptin (Genentech, Inc, South San Francisco, Calif) similarly sensitized H358 cell to paclitaxel (unpublished data). Moreover, there was a positive linear correlation between the magnitude of 17 AAGA-mediated reduction of the p185 oncoprotein and the multiplicity of reduction in paclitaxel $\mathrm{IC}_{50}$ (the magnitude of chemosensitization) in NSCLC cells that positively responded to the combination treatment (data not shown). These observations, in conjunction with other published reports, ${ }^{21,23}$ confirm that enhancement of paclitaxel's toxic effects in cells that overexpress p185 is mediated at least in part by inhibition of p185 expression.

The multidrug resistance ( $m d r$ ) gene is known to confer chemoresistance in cancer cells; however, paclitaxel resistance in cells exhibiting p185 overexpression does not seem to involve the $m d r$ pathway. ${ }^{5,24}$ Typically, $m d r$ 1 messenger RNA levels are low or undetectable in most NSCLCs, except those rare tumors that exhibit features of neuroendocrine differentiation. ${ }^{24}$ Expression of $m d r$ is not induced in cells engineered to express high levels of p185. ${ }^{6}$ Recent experiments by Yu and associates $^{25}$ have demonstrated that p185 overexpression induces upregulation of $\mathrm{p} 21 /$ cip 1 expression, which inhibits activation of $\mathrm{p} 34 / c d c 2$ required for paclitaxelinduced apoptosis. These observations provide the molecular basis for use of p185 antagonists in the management of lung and other solid tumors that frequently exhibit paclitaxel resistance.

In vivo toxicity profiles of geldanamycin and 17AAGA have been documented in small-animal models; renal and hepatic toxicities were dose-limiting events. ${ }^{26,27}$ However, the nanomolar concentrations required to mediate paclitaxel sensitization observed in our studies are well below the maximal tolerable doses reported in animal toxicity studies. ${ }^{26,27}$ Collectively these data support the evaluation of the combination of paclitaxel and 17-AAGA in the treatment of patients with NSCLCs exhibiting p185 overexpression.

\section{REFERENCES}

1. Akiyama T, Sudo C, Ogawara H, Toyoshima K, Yamamot T. The product of the human c-erb-b2 gene: a 185-kilodalton glycoprotein with tyrosine kinase activity. Science 1986;232:1644-6.

2. Alaoui-Jamali MA, Paterson J, Al Moustafa AE, Yen L. The role of ErbB-2 tyrosine kinase receptor in cellular intrinsic chemoresistance: mechanisms and implications. Biochem Cell Biol 1997; 75:315-25.

3. Tsai CM, Chang KT, Wu LH, Chen JY, Gazdar AF, Mitsudomi T, et al. Correlations between intrinsic chemoresistance and HER2/neu gene expression, p53 gene mutations, and cell proliferation characteristics in non-small cell lung cancer cell lines. Cancer Res 1996;56:206-9.

4. Tsai CM, Yu D, Chang KT, Wu LH, Perng RP, Ibrahim NK, et al. Enhanced chemoresistance by elevation of p185neu levels in HER-2/neu-transfected human lung cancer cells. J Natl Cancer Inst 1995;87:682-4.

5. Yu D, Liu B, Tan M, Li J, Wang SS, Hung MC. Overexpression of c-erbB-2/neu in breast cancer cells confers increased resistance to Taxol via mdr-1-independent mechanisms. Oncogene 1996;13:1359-65.

6. You XL, Yen L, Zeng-Rong N, Al Moustafa AE, Alaoui-Jamali MA. Dual effect of erbB-2 depletion on the regulation of DNA repair and cell cycle mechanisms in non-small cell lung cancer cells. Oncogene 1998;17:3177-86.

7. Slamon DJ, Clark GM, Wong SG, Levin WJ, Ullrich A, McGuire WL. Human breast cancer: correlation of relapse and survival with amplification of the HER-2/neu oncogene. Science 1987; 235:177-82.

8. Diez M, Pollán M, Maestro M, Torres A, Ortega D, Gómez A, et al. Prediction of recurrence by quantification of $\mathrm{p} 185$ neu protein in non-small-cell lung cancer tissue. Br J Cancer 1997;75:684-9.

9. Hsieh CC, Chow KC, Fahn HJ, Tsai CM, Li WY, Huang MH, et 
al. Prognostic significance of HER-2/neu overexpression in stage I adenocarcinoma of lung. Ann Thorac Surg 1998;66:1159-63.

10. Supko JG, Hickman RL, Grever MR, Malspeis L. Preclinical pharmacologic evaluation of geldanamycin as an antitumor agent. Cancer Chemother Pharmacol 1995;36:305-15.

11. An WG, Schnur RC, Neckers L, Blagosklonny MV. Depletion of p185erbB2, Raf-1 and mutant p53 proteins by geldanamycin derivatives correlates with antiproliferative activity. Cancer Chemother Pharmacol 1997;40:60-4.

12. Schulte TW, Neckers L. The benzoquinone ansamycin 17-allylamino-17-demethoxygeldanamycin binds to HSP90 and shares important biologic activities with geldanamycin. Cancer Chemother Pharmacol 1998;42:273-9.

13. Chavany C, Mimnaugh E, Miller P, Bitton R, Nguyen P, Trepel J, et al. p185erbB2 binds to GRP94 in vivo: dissociation of the p185erbB2/GRP94 heterocomplex by benzoquinone ansamycins precedes depletion of p185erbB2. J Biol Chem 1996;271:4974-7.

14. Mimnaugh EG, Chavany C, Neckers L. Polyubiquitination and proteasomal degradation of the $\mathrm{p} 185 \mathrm{c}$-erbB-2 receptor proteintyrosine kinase induced by geldanamycin. J Biol Chem 1996; 271:22796-801.

15. Miller P, DiOrio C, Moyer M, Schnur RC, Bruskin A, Cullen W, et al. Depletion of the $e r b \mathrm{~B}-2$ gene product $\mathrm{p} 185$ by benzoquinoid ansamycins. Cancer Res 1994;54:2724-30.

16. Krishan A. Rapid flow cytofluorometric analysis of mammalian cell cycle by propidium iodide staining. J Cell Biol 1975;66:188-93.

17. Donaldson KL, Goolsby GL, Wahl AF. Cytotoxicity of the anticancer agents cisplatin and Taxol during cell proliferation and the cell cycle. Int J Cancer 1994;57:847-55.

18. Fueyo J, Gomez-Manzano C, Puduvalli VK, Martin-Duque P, Perez-Soler R, Levin VA, et al. Adenovirus-mediated p16 transfer to glioma cells induces G1 arrest and protects from paclitaxel and topotecan: implications for therapy. Int J Oncol 1998;12:665-9.

19. Petit AM, Rak J, Hung MC, Rockwell P, Goldstein N, Fendly B, et al. Neutralizing antibodies against epidermal growth factor and ErbB-2/neu receptor tyrosine kinases down-regulate vascular endothelial growth factor production by tumor cells in vitro and in vivo: angiogenic implications for signal transduction therapy of solid tumors. Am J Pathol 1997;151:1523-30.

20. Yu D, Wang SS, Dulski KM, Tsai CM, Nicolson GL, Hung MC. c-erbB-2/neu overexpression enhances metastatic potential of human lung cancer cells by induction of metastasis-associated properties. Cancer Res 1994;54:3260-6.

21. Baselga J, Norton L, Albanell J, Kim YM, Mendelsohn J. Recombinant humanized anti-HER2 antibody (Herceptin) enhances the antitumor activity of paclitaxel and doxorubicin against HER2/neu overexpressing human breast cancer xenografts. Cancer Res 1998;58:2825-31.

22. Barnes MN, Deshane JS, Siegal GP, Alvarez RD, Curiel DT. Novel gene therapy strategy to accomplish growth factor modulation induces enhanced tumor cell chemosensitivity. Clin Cancer Res 1996;2:1089-95

23. Ueno NT, Yu D, Hung MC. Chemosensitization of HER-2/neuoverexpressing human breast cancer cells to paclitaxel (Taxol) by adenovirus type 5 E1A. Oncogene 1997;15:953-60.

24. Lai SL, Goldstein LJ, Gottesman MM, Pastan I, Tsai CM, Johnson BE, et al. MDR1 gene expression in lung cancer. J Natl Cancer Inst 1989;81:1144-50.
25. Yu D, Jing T, Liu B, Yao J, Tan M, McDonnell TJ, et al. Overexpression of ErbB2 blocks Taxol-induced apoptosis by upregulation of p21Cip1, which inhibits p34Cdc2 kinase. Mol Cell 1998;2:581-91.

26. Eiserman JL, Sentz DL, Zuhowski EG, Ramsland TS. Plasma pharmacokinetics and tissue distribution of 17-allylaminogeldanamycin (NSC330507), a prodrug for geldanamycin, in CD2F1 mice and Fisher 344 rats [abstract]. Proc AACR 1997; 38:308.

27. Page J, Heath J, Fulton R, Yalkowsky E. Comparison of geldanamycin (NSC122750) and 17-allylaminogeldanamycin (NSC330507D) toxicity in rats [abstract]. Proc AACR 1997;38: 308.

\section{Discussion}

Dr Mark K. Ferguson (Chicago, Ill). Is 17-AAGA something that potentially can be used clinically?

Dr Nguyen. Yes. The National Cancer Institute is setting up a phase I clinical trial with this compound for solid tumors. Three other cancer centers, Memorial Sloan-Kettering Cancer Center included, would participate in this clinical trial.

Dr Ferguson. Is there some time frame for advance administration of the 17-AAGA that would not induce cell-cycle reversion to $G_{1}$ phase?

Dr Nguyen. We have not looked into that. The compound 17-AAGA has been shown to deplete p185 protein maximally after 8 hours of exposure. Pretreatment of cells for 8 hours before paclitaxel thus might have a beneficial effect, but we have not looked into that yet.

Dr Valerie W. Rusch (New York, NY). Is this a p53-independent event?

Dr Nguyen. Yes. The $\mathrm{G}_{1}$ arrest has been shown to be occurring in cells that have mutated or delete p53. For example, $\mathrm{H} 1299$ and $\mathrm{H} 358$ are p53-null. The $\mathrm{G}_{1}$ arrest is a p53-independent phenomenon.

Dr Rusch. Was the normal human bronchial epithelial cell line that you used the BEA52B cell line or a different cell line?

Dr Nguyen. The normal human bronchial epithelial cells were human cells that we purchased from Clonetics. These primary cells grow for about 4 to 6 passages and terminally differentiate.

Dr Rusch. So they were from your own short-term cultures that you set up yourself?

Dr Nguyen. The normal human bronchial epithelial cells are primary cells, not a line cell, and maintained in short-term culture according to the manufacturer's instruction.

Dr Rusch. Was there any direct cytotoxic effect on the human cells with this agent?

Dr Nguyen. We observed that when we grew the normal human cells to confluence in culture for 96 hours and treated that culture with the drug combination there was no enhanced toxic effect of paclitaxel with this combination. So the drug combination seems to be selective for proliferating malignant cells. 